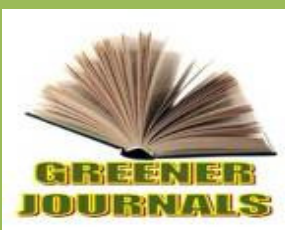

\title{
Assessment of the Potential Water Quality effects Resulting from the Release of Vinasse, from the Bioethanol Demonstration Plant, into the Surrounding Waterway
} Abrahim BN ${ }^{1}$, Clementson $\mathrm{C}^{\star}$, Homenauth $\mathrm{O}^{2}$

\author{
National Agricultural Research and Extension Institute, Mon Repos, East Coast Demerara, \\ Guyana.
}

Emails:1narie_abrahim@ hotmail.com,2oudhohomenauth@gmail.com

\section{ARTICLE INFO}

Article No.: 022416043

DOI: 10.15580/GJAS.2016.3.022416043

Submitted: $23 / 02 / 2016$

Accepted: 26/02/2016

Published: 28/03/2016

${ }^{*}$ Corresponding Author

Clementson $C$

E-mail:kemba_cc@yahoo.com

\section{Keywords:}

Albion Bioethanol Demonstration Plant, Water Quality, Physical

Parameters, Chemical

Parameters
Guyana commissioned its very own Bioethanol Demonstration Plant in Albion, Berbice in August, 2013. Unfortunately, the plant releases an effluent (vinasse) that could be environmentally unsafe if not properly channeled or utilized.

This study entailed an assessment of the effects on water quality due to the release of vinasse into the waterway surrounding the Albion Bioethanol Demonstration Plant. Water samples were collected at four locations along the waterway; at the point of effluent discharge, five metres downstream, twenty metres and one hundred metres downstream. These samples were collected at five different time periods. The first set of samples was collected on February 19, 2015 which was two weeks before resumption of plant operations. Samples were also collected February 27, 2015 upon resumption of operations, March 26, 2015 one month after, April 24, 2015 two months after operation commenced and May 28, 2015 one week after the end of seasonal operation. The water samples were analyzed for $\mathrm{pH}$, turbidity, electrical conductivity, total suspended solids, total dissolved solids, chemical oxygen demand, nitrates, orthophosphates and heavy metals including Magnesium, Aluminum, Iron, Manganese, Copper, Cadmium, Chromium, Cobalt, Nickel, Lead andZinc.

The study indicated that vinasse is acidic in nature and upon dumping, increases the acidity of the canal. Also, the effluent has a high chemical oxygen demand, total suspended solids, total dissolved solids and turbidity which may be the reason for the water samples having such high concentrations of the above listed. Additionally, these parameters revealed a general increase with time and decrease with distance. Contrary to these, the remaining chemical parameters showed varying trends with respect to both distance and time. Furthermore, the analyses revealed that the concentrations of the heavy metals were high even before the plant commenced operations; this may imply that there was leaching of the various metals from the factory into the water course. Moreover, the presence of dissolved organic matter within the water may have resulted in chemical reactions with the heavy metals leading to the formation of aqueouscomplexes.

The concentrations of many of the physical and chemical parameters tested in the water course indicated that the levels were above the maximum recommended limits set out by the World Health Organization and the Food and Agriculture Organization. 


\section{ABBREVIATION}

EC: Electrical Conductivity TSS: Total Suspended Solids TDS: Total Dissolved Solids

COD: Chemical Oxygen Demand MG: Magnesium

Al: Aluminum Fe: Iron

$\mathrm{Mn}$ : Manganese $\mathrm{Cu}$ : Copper

Cd: Cadmium

Cr:Chromium Co: Cobalt Ni:Nickel

$\mathrm{Pb}$ : Lead Zn: Zinc

GUYSUCO: Guyana Sugar Corporation WHO: World Health Organization

FAO: Food and Agriculture Organization

\section{INTRODUCTION}

The development of a green economy is a defining issue in Guyana. It has been recognized that energy is directly connected with the key challenges of climate change, poverty and food security. The country has realized that the importation of fuel which consumes more than quarter of the gross domestic product has contributed significantly to a depressed economy. In order for Guyana to facilitate development and to avoid further environmental degradation various forms of renewable energy are currently being explored, bio-energy being a prominent consideration because of Guyana's geographic location and fertile arable lands. This consideration led to the establishment of the Albion Bioethanol Demonstration Plant.

The plant operates on a seasonal basis as it requires the steam and molasses from the sugar factory for its operations. Molasses is mixed with yeast and water and left for approximately thirty six hours to ferment. It then passes through a distillation unit where hydrous alcohol is produced. Furthermore, the water content of the ethanol is reduced to $0.4 \%$ producing bioethanol with a purity level of $99.6 \%$ ethanol. The plant is designed to produce at least one thousand liters of ethanol per day. However, in this production process, an effluent is released. This bioethanol effluent is commonly referred to as "vinasse".

The Albion Bioethanol Demonstration Plant produces vast amounts of vinasse on a daily basis. According to Abrahim, Clementson and Homenauth (2015), for every liter of ethanol produced, ten litres of vinasse is released. Much of the vinasse produced is released directly into an open water course through a network of pipelines. This water way is the main canal located south of the plant and is connected to various surrounding canals attached to the cane fields.

Vinasse is a dark brown substance with a pungent odour containing ninety three percent of water with the remaining seven percent being solids. Studies have shown that vinasse is acidic in nature and the low $\mathrm{pH}$ can be attributed to the presence of the organic acids and hydrogen ions (Ahmed, Sulieman and Hardallou, 2013). Tate and Lyle (cited in Technical Evaluations Report- Vinasse, 2013) noted that the effluent is soluble in water and contains high levels of
Potassium, Magnesium, Calcium, Sulphur and Nitrogen. Additionally, studies conducted in Mauritius revealed that the effluent is corrosive and contains high concentrations of heavy metals including iron, copper, manganese and zinc (Soobadar and Kwong, 2015). A study conducted by Pereira and Pereira (2008) showed that metal mobilization of iron, copper, cadmium, chromium, nickel, lead, cobalt and zinc could also occur.

Prado, Caione and Campos (2013) indicated that the polluting nature of the substance is due to its low $\mathrm{pH}$, high chemical and biological requirement for oxygen. Studies in Brazil have indeed confirmed these environmental threats where uncontrolled dumping of the effluent in open waterways led to the abandonment of the area (Clancy, 2013). Moreira (cited in Clancy, 2013) noted that the release on vinasse can cause serious environmental degradation with detrimental effects to aquatic ecosystems. However, Brazil recognized the extent of the environmental damages due to inconsiderate dumping of the vinasse and has since developed regulations and policies to ensure that the effluent is not released in water courses.

The vinasse released from the Albion Bioethanol Plant can therefore have catastrophic effects on the aquatic environment of this area. Therefore, this study was done to assess the effects on water quality due to the release of vinasse into the waterway surrounding the Albion Bioethanol Plant.

\section{Research Objectives}

The general aim of this study is to assess the effects on water quality due to the release of vinasse into the waterway surrounding the Bioethanol Demonstration Plant located in Albion, Berbice. The specific objectives are:

1. To determine a baseline for the assessment of water quality at the Bioethanol plant.

2. To determine the effects of the release of vinasse into the surrounding waterways of the Bioethanol plant for different time periods during operations.

3. To assess the impact of the release of vinasse into the surrounding waterways of the plant after the end of the seasonal operation. 


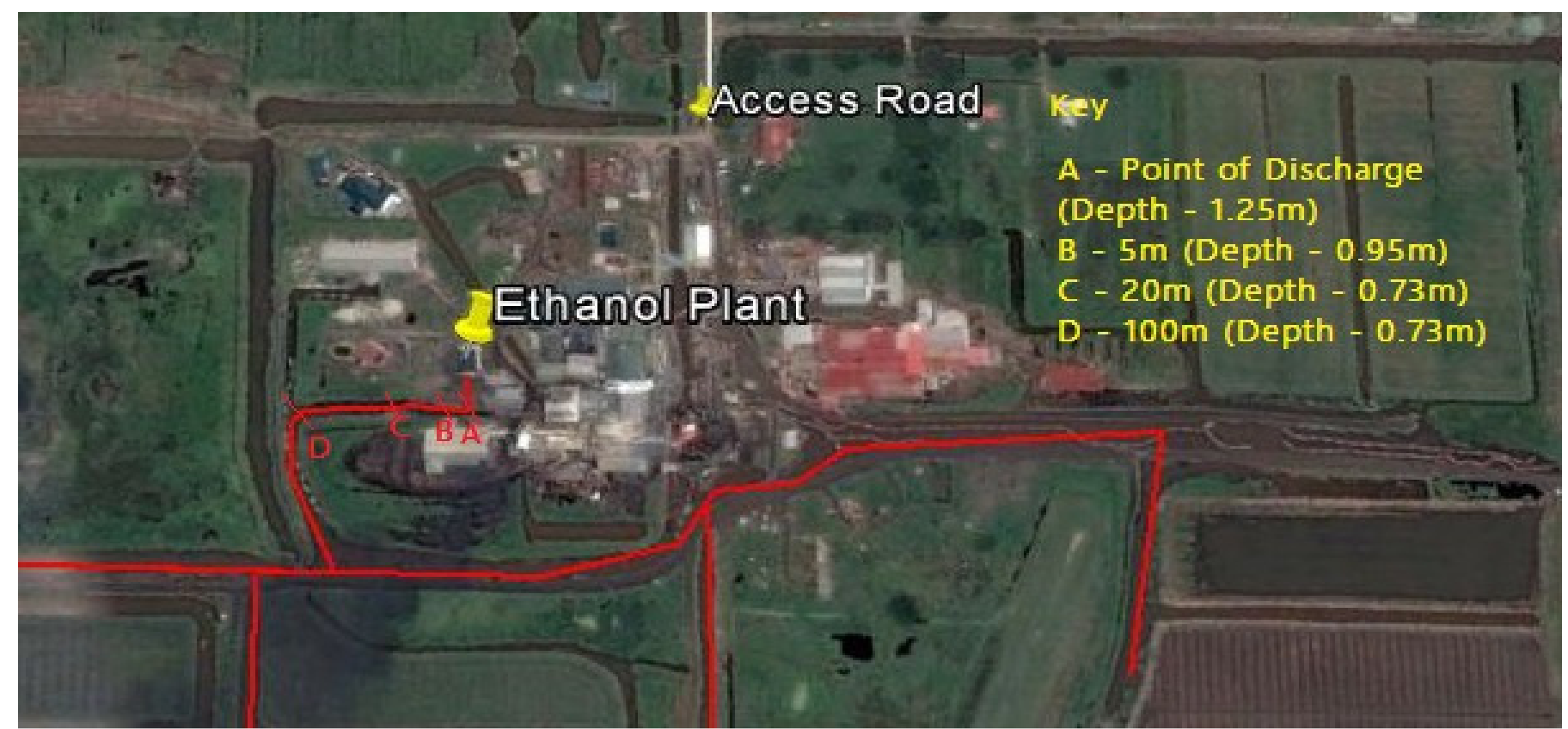

Figure 1: Layout of the Albion Bioethanol Plant with the Sampling Points and Varying Depth Readings (Source: Google Earth, 2013)

\section{RESEARCH METHODOLOGY}

This research was conducted at the Bioethanol Demonstration Plant located in the Albion Sugar Estate Compound, Albion Berbice. The vinasse produced by the plant is cooled via a heat exchanger and released into a canal on the southern side of the plant.

Water samples were collected at four locations along the waterway as illustrated in figure 1; at the point of effluent discharge, five metres downstream, twenty metres downstream and one hundred metres downstream. Samples were collected in triplicates from both edges and in the middle of the canal by the use of a fifteen litre plastic bucket, at the different collection points. $600 \mathrm{ml}$ sample bottles were placed in the bucket and filled, with care being taken to prevent air bubbles. These samples were labeled and placed in an air conditioned vehicle and transported approximately sixty four miles to NAREI Compound, Mon Repos, East Coast Demerara. The samples were placed in cold storage for not more than two days then taken to Guyana Sugar Corporation's Laboratory (GUYSUCO), La Bonne Intention, East Coast Demerara for analysis.

Figure 1 shows the layout of the Albion Bioethanol Plant with the Sampling Points and Varying Depth Readings.

The first set of samples was collected on February 19, 2015, two weeks before the plant resumed operations for the 2015 first crop. This was done so as to establish a baseline for this research. On February 27, 2015, the week the plant resumed operations, the second batch of samples were collected. Other samples were taken on March 26 and April 24, 2015 being about one and two months after operations for that crop commenced respectively. The final water samples were collected on May 28, 2015, approximately one (1) week after completion of plant operations for that crop. The water samples were analyzed for various physical and chemical parameters. Table 1 below shows the Physical and Chemical parameters determined for each water sample.

The laboratory techniques used to analyze the physical and chemical parameters of the water samples at GUYSUCO laboratory were extracted from the "Standard Methods for the Examination of Water and Wastewater" by the American Public Health Association (1999). Each parameter was analyzed based on the recommended methodology as stated within the manual. The methodology is similar to that used by Viven, Caleb and Lekwot (2012) in a study done to assess the public health effects of effluent discharge of Kaduna Refinery into River Romi.

A conductivity meter was used to ascertain the ability of the water sample to carry an electric charge, a characteristic commonly referred to as electrical conductivity. The total solids found in water comprise of total suspended solids and total dissolved solids. To determine the total dissolved solids, $20 \mathrm{ml}$ of the water was filtered and placed in a crucible. This was placed in an oven at $105^{\circ} \mathrm{C}$ until constant weight was obtained. The total suspended solids were found using a similar technique where a dried filter paper was weighed and placed in a sintered glass funnel. This was placed in a vacuum flask and connected to a vacuum pump. Upon filtering, the filter paper containing the residue was removed and placed in an oven at $105^{\circ} \mathrm{C}$ until constant 
weight was obtained. A turbidimeter was used to determine the turbidity of the water samples. The level of turbidity depends on the clarity of the water and a turbidimeter measures the amount of light scattered by particles suspended in the substance.

The chemical parameters were also found using methodologies outlined in the manual. A pH meter was used to determine the $\mathrm{pH}$ of the samples. The chemical oxygen demand of each water sample was found via titration using potassium dichromate. The chemical oxygen demand is a measure of the organic matter found in the water. The titrimetricmethod implies that many organic compounds can be oxidized to carbondioxide with the use of potassium dichromate under acidic conditions. In this process, the potassium dichromate is reduced to $\mathrm{Cr}^{3+}$ which is then used as a measure of organic matter in the sample. The concentrations of nitrates and orthophosphates were done using a chemical reaction resulting in a colour change, where a vernier colorimeter was used to measure the intensity of such change. The heavy metals levels were determined with the use of an atomic absorption spectrometer which relies on the Beer Lambert's Law. With this equipment, the sample is aspirated into a flame and atomized. A light beam then passes through the flame into a monochromator. The light then hits a detector which measures the amount of light absorbed by the atomized sample. Each heavy metal has its own distinctive absorption wavelength and the energy absorbed by such is proportional to the concentration of the element within a specific range.

After laboratory analysis, the Statistix 9.0 Software and Microsoft Excel were then used to statistically analyze and represent the data. Each parameter (physical and chemical) was evaluated individually with respect to the variables of distance away from the point of discharge and time as the plant commenced operations.

Table 1: Physical and Chemical Parameters determined for each water sample

\begin{tabular}{|c|c|}
\hline Physical Parameters & Chemical Parameters \\
\hline Electronic conductivity (EC) & $\mathrm{pH}$ \\
\hline Total suspended solids (TSS) & Chemical oxygen demand (COD) \\
\hline Turbidity & Nitrates \\
\hline Total dissolved solids (TDS) & Orthophosphates \\
\hline & Magnesium (Mg) \\
\hline & Aluminum (Al) \\
\hline & Iron (Fe) \\
\hline & Manganese (Mn) \\
\hline & Copper (Cu) \\
\hline & Cadmium (Cd) \\
\hline & Chromium (Cr) \\
\hline & Cobalt (Co) \\
\hline & Nickel (Ni) \\
\hline & Lead (Pb) \\
\hline & Zinc (Zn) \\
\hline
\end{tabular}

\section{RESULTS}

The vinasse produced by the Albion Bioethanol Demonstration Plant contains a high electronic conductivity and elevated levels of turbidity, total dissolved solids, and total suspended solids. The analysis also revealed that the vinasse is acidic and has a high chemical oxygen demand. The organic content of the effluent is the main contributor of such elevated levels. Additionally, it was found that the effluent contains varying concentrations of heavy metals.

Table 2 below shows the Laboratory analysis of the vinasse produced at the Albion Bioethanol Demonstration Plant. 
Table 2: Laboratory analysis of the vinasse produced at the Albion Bioethanol Demonstration Plant

\begin{tabular}{|c|c|}
\hline Parameters & Concentration (mg/L) \\
\hline $\mathrm{pH}$ & 4.05 \\
\hline Electronic Conductivity & 17.5 \\
\hline Nitrate & $\mathrm{Nd}$ \\
\hline Turbidity & 1180 \\
\hline Total Suspended Solids & 1150 \\
\hline Chemical Oxygen Demand & 49600 \\
\hline Aluminum & 1.71 \\
\hline Cobalt & 0.17 \\
\hline Lead & 0.20 \\
\hline Magnesium & 108 \\
\hline Nickel & 0.34 \\
\hline Chromium & 0.26 \\
\hline Cadmium & 0.07 \\
\hline Manganese & 5.52 \\
\hline Zinc & 1.03 \\
\hline Iron & 602 \\
\hline Copper & 0.56 \\
\hline Phosphorus & 1.00 \\
\hline
\end{tabular}

Table 3: Showing the Food and Agriculture Organization Industrial waste Discharge Regulation and the World Health Organization Maximum Permissible Limits for some of the Parameters tested

\begin{tabular}{|c|c|c|c|}
\hline Parameter & $\begin{array}{l}\text { Food and Agriculture } \\
\text { Organization Industrial Waste } \\
\text { Discharge regulation (mg/l) }\end{array}$ & $\begin{array}{l}\text { World Health Organization } \\
\text { Maximum Permissible Limits } \\
\text { (mg/l) }\end{array}$ & $\begin{array}{l}\text { Average Concentrations of } \\
\text { the Tested Parameters at the } \\
\text { Albion Bioethanol Plant (mg/l) }\end{array}$ \\
\hline pH & $6-9.5$ & $6.5-8$ & 5.554 \\
\hline COD & ----- & 40 & 6710.33333 \\
\hline TDS & 3.5 & 30 & 0.00062 \\
\hline TSS & 30 & 250 & 87.75 \\
\hline Phosphorus & 1.0 & --- & 1.66 \\
\hline Magnesium & ----- & ---- & 8.087 \\
\hline Manganese & 1.0 & --- & 0.614 \\
\hline Iron & 2.0 & ---- & 4.93783 \\
\hline Lead & 0.2 & --- & 0.37579 \\
\hline Zinc & 1.0 & --- & 0.03521 \\
\hline Cadmium & 0.03 & 0.003 & 0.02479 \\
\hline Turbidity & ---- & $5(\mathrm{NTU})$ & 66.8 \\
\hline
\end{tabular}

Statistical analysis of the data retrieved from the laboratory analyses of the water samples revealed that at the point of effluent discharge, the water sample showed greater acidity than further away from the plant. Additionally, as the plant continued operations over the next few months, the acidity in the water along the canal path increased. This can be attributed to the acidic nature of the vinasse released. The $\mathrm{pH}$ values for the point of discharge were lower than the recommended maximum permissible level of both the World Health Organization (WHO) and the Food and Agriculture Organization (FAO). Table 3 above shows the Food and Agriculture Organization Industrial waste Discharge Regulation and the World Health Organization Maximum Permissible Limits for some of the Parameters tested. 
Table 4: Showing the Average concentrations of the parameters tested at the different distances for the various time periods

\begin{tabular}{|c|c|c|c|c|c|c|c|c|c|c|c|c|c|c|c|}
\hline Time & Distance & $\mathrm{pH}$ & EC & TDS & TSS & Turbidity & COD & $\mathbf{P}$ & $\mathrm{Al}$ & $\mathbf{P b}$ & $\mathrm{Fe}$ & $\mathrm{Zn}$ & Mn & Cd & Mg \\
\hline \multirow[b]{4}{*}{$\mathrm{T} 1$} & 0 & 5.53 & 0.20 & 0.00 & 46.33 & 56.73 & 248.00 & 2.95 & 1.73 & 1.58 & 4.14 & 0.05 & 0.54 & 0.01 & 4.55 \\
\hline & 5 & 5.80 & 0.20 & 0.00 & 63.33 & 70.30 & 240.00 & 2.16 & 2.02 & 0.13 & 4.11 & 0.04 & 0.50 & 0.01 & 4.55 \\
\hline & 20 & 6.03 & 0.20 & 0.00 & 59.67 & 70.83 & 116.00 & 2.01 & 2.47 & 0.08 & 3.58 & 0.03 & 0.43 & 0.01 & 3.37 \\
\hline & 100 & 6.19 & 0.10 & 0.00 & 60.00 & 85.13 & 216.00 & 2.22 & 4.70 & $\mathrm{Nd}$ & 1.85 & 0.05 & 0.24 & 0.00 & 2.72 \\
\hline \multirow[b]{4}{*}{ T2 } & 0 & 4.76 & 0.40 & 0.00 & 87.67 & 91.33 & 80085.33 & 2.88 & 0.38 & 0.17 & 20.67 & 0.03 & 0.95 & 0.03 & 18.20 \\
\hline & 5 & 5.21 & 0.10 & 0.00 & 62.33 & 74.33 & 14805.33 & 4.56 & 0.33 & 0.24 & 10.73 & 0.01 & 0.72 & 0.03 & 9.76 \\
\hline & 20 & 5.54 & 0.10 & 0.00 & 67.00 & 104.67 & 141.33 & 2.25 & 0.67 & 0.54 & 7.68 & 0.01 & 0.44 & 0.03 & 7.04 \\
\hline & 100 & 5.73 & 0.10 & 0.00 & 70.33 & 149.33 & 50.67 & 0.72 & 0.82 & 0.80 & 6.25 & 0.00 & 0.21 & 0.03 & 5.24 \\
\hline \multirow[b]{4}{*}{ T3 } & 0 & 4.96 & 0.30 & 0.00 & 69.00 & 37.03 & 653.33 & 0.91 & 1.04 & 0.03 & 7.10 & 0.01 & 1.47 & 0.00 & 3.19 \\
\hline & 5 & 5.20 & 0.30 & 0.00 & 44.33 & 29.67 & 362.67 & 0.89 & 1.10 & 0.04 & 6.35 & 0.02 & 1.41 & 0.01 & 7.59 \\
\hline & 20 & 5.46 & 0.30 & 0.00 & 63.00 & 17.83 & 261.33 & 0.90 & 1.23 & 0.02 & 6.02 & 0.02 & 1.31 & 0.00 & 7.32 \\
\hline & 100 & 5.50 & 0.10 & 0.00 & 44.33 & 20.80 & 226.67 & 1.23 & 1.25 & 0.69 & 1.70 & 0.01 & 0.32 & 0.00 & 4.89 \\
\hline \multirow[b]{4}{*}{$\mathrm{T} 4$} & 0 & 5.10 & 0.30 & 0.00 & 100.00 & 146.00 & 8266.67 & 2.29 & 7.07 & 0.70 & 5.99 & 0.07 & 0.95 & 0.03 & 19.53 \\
\hline & 5 & 5.46 & 0.40 & 0.00 & 193.33 & 137.67 & 2000.00 & 1.43 & $\mathrm{Nd}$ & 0.67 & 4.71 & 0.08 & 0.93 & 0.03 & 19.63 \\
\hline & 20 & 6.00 & 0.30 & 0.00 & 113.33 & 84.07 & 218.67 & 1.59 & $\mathrm{Nd}$ & 0.50 & 3.46 & 0.07 & 0.71 & 0.02 & 15.50 \\
\hline & 100 & 6.15 & 0.20 & 0.00 & 600.00 & 129.60 & 189.33 & 0.38 & 0.02 & 0.42 & 3.91 & 0.06 & 0.32 & 0.03 & 14.83 \\
\hline \multirow[b]{4}{*}{ T5 } & 0 & 5.24 & 0.30 & 0.00 & 2.50 & 7.47 & 34.67 & 1.05 & 0.22 & 0.10 & 0.04 & 0.00 & 0.22 & 0.04 & 3.39 \\
\hline & 5 & 5.64 & 0.30 & 0.00 & 2.50 & 9.77 & 13.33 & 1.12 & 0.20 & 0.12 & 0.10 & 0.00 & 0.22 & 0.04 & 3.54 \\
\hline & 20 & 5.75 & 0.30 & 0.00 & 2.00 & 6.27 & 24.00 & 0.86 & 0.20 & 0.14 & 0.04 & 0.00 & 0.20 & 0.03 & 3.60 \\
\hline & 100 & 5.83 & 0.23 & 0.00 & 4.00 & 7.17 & 32.00 & 0.79 & 0.25 & 0.18 & 0.31 & 0.01 & 0.19 & 0.02 & 3.29 \\
\hline
\end{tabular}


Table 4 above shows the Average concentrations of the parameters tested at the different distances for the various time periods.

For most of the water samples, the electrical conductivity was primarily low and even constant for some of the testing periods. A low electrical conductivity indicated that much of the dissolved solids present in the sample were more of a biological nature and as such the interaction of electrically charged particles were minimal. A similar trend was recognized with the total dissolved solids. Total dissolved solids consist of the inorganic salts and a small amount organic matter found in water. A low total dissolved solids concentration may be because the saturation point for dissolution of vinasse in water was achieved early. These levels indicated were much lower than the limits set out by WHO and FAO.

The analysis revealed an increasing trend in the total suspended solids with respect to time and distance. It must be noted that the bioethanol plant is not the only source of discharge to the tested water body; the sugar factory may have contributed to an increasing trend with respect to distance. On average, the total suspended solid levels conform to the limits required by the WHO but are far greater than that of FAO.

The turbidity of the water showed no distinct trend. This varying trend may be attributed to high rainfall reading for the latter periods of testing. It was recognized that before the plant commenced operations, the turbidity in the water was high. This indicated that other factors may have contributed to the high turbidity of the water and that it cannot be sourced directly to the vinasse. The level of turbidity in the water course at each distance for every time period is much greater than the WHO maximum permissible limit.

Tests for phosphorus indicate that the phosphorus levels were constant and that there were no significant differences among the time periods. Generally, the level of phosphorus in the water course is greater than the FAO Recommended level with respect to distance and time.

With respect to the heavy metals, aluminum, zinc, iron and lead, the levels were high even before the plant commenced operations. This indicated that there may have been leaching of these elements from the factory into the waterway. In the factory, there are possible aluminum, zinc, iron and lead components which may have contributed to the high levels in the water prior to operations.

With respect to magnesium, it was recognized that there was a general increase with time and a decrease with distance. It can therefore be said that the release of vinasse into the waterway was the main source of magnesium which may have been absorbed or diluted as the water progressed along the canal path.

\section{ACKNOWLEDGMENT}

The authors would like to express sincere gratitude to the Guyana Sugar Corporation Laboratory for the
A similar trend was observed for manganese as it increased with time and decreased with distance. However, cadmium showed varying trends with respect to distance and time. It can therefore be implied that the cadmium may have come from the vinasse released into the water. This varying trend may be attributed to the rainfall patterns observed during the periods of testing.

Laboratory analyses were also conducted for other elements including nitrates, cobalt, chromium, nickel and copper. However, these elements were not detectable within the water samples.

\section{CONCLUSION}

This study was done to assess the effects on water quality due to the release of vinasse into the waterway surrounding the Albion Bioethanol Demonstration Plant. The research was conducted for a period of February 2015 to May 2015 before, during and after plant operations.

The study revealed that vinasse is acidic, has a high chemical oxygen demand, total dissolved solids, total suspended solids and turbidity content. As such, the levels of these parameters were elevated in most of the samples which showed a general increase with time of operations and a decrease with distance from the plant. It can be concluded that the release of vinasse accounted for such levels and trends of the abovementioned parameters in the water course. On the other hand, the remaining chemical parameters showed varying trends in the tested water samples. With the heavy metals, the analyses indicated that levels were high even before the plant commenced operations. This implies that such results may have been due to leaching since the factory contains possible aluminum, zinc, iron and lead components. It was also recognized that due to the presence of the dissolved organic matter in the vinasse, heavy metals may have undergone chemical reactions resulting in the formation of aqueous complexes. Additionally, elements such as magnesium, manganese and cadmium indicated varying concentrations with respect to time and distance.

This study proves that the release of vinasse into the open waterway at the Albion Bioethanol Plant is environmentally unsafe and hazardous to the aquatic environment and the groundwater quality. The effluent contributes to increased levels of the tested physical and chemical parameters which are greater than the recommended levels set out by the World Health Organization and Food and Agriculture Organization. It can be concluded that vinasse is indeed a polluting effluent and avenues for treatment, use and disposal of the substance at the plant should be explored.

chemical and physical analyses conducted on the water samples. Great thanks are also extended to Mr Vickram Persaud for his assistance during the samplingperiod. 


\section{REFERENCES}

Abrahim, B., Clementson, C., and Homenauth, O. (2015). An Investigation into the potential impacts on air quality during operations of the Albion Bioethanol Plant in Berbice, Guyana. Global Scholastic Research Journal of Multidisciplinary. 1 (13): 1-8.

Ahmed, O., Sulieman, A., and El Hradallou, S. (2013). Physiochemical, Chemical and Microbiological Characteristics of Vinasse, A By-product from the Ethanol Industry. American Journal of Biochemistry. 3 (3): 80-83.

American Public Health Association, A. W. (1999). Standard Methods for the Examination of water and Wastewater Part 1000.

Clancy, J. (2013). Biofuels and Rural Poverty. Routledge. New York, 1-195.

Food and Agriculture Organization (1994). FAO Industrial Waste Discharge Regulation No. 180 Part 1. Vientiane, 1- 12.
Pereira, S., and Pereira, P. (2008). Environmental Aspects in Ethanol production Related to Vinasse Disposal and Groundwater. International Geological Congress. Brazil.

Prado, R., Caione, G., and Campos, C. (2013). Review Article: Filter Cake and Vinasse as Fertilizer Contributing to Conservation Agriculture. Hindawi Publishing Corporation. 2013: 1-8.

Pesticide Research Institute for the USDA National Organic Program (2013). Technical Evalution Report Vinasse. Pesticide Research Institute for the USDA National Organic Program. 1-12.

Soobadar, A., and Kwong, R. (2015). AG8 Impact of Fertilization of Sugar cane with High rates of Vinasse on Groundwater Quality in Mauritius. Mauritius Sugar Industry Research Institute.

Viven, C., Caleb, A., and Lekwot, V. (2012). Public Health Effects of Effluent Discharge of Kaduna Refinery into River Romi. Greener Journals of Medical Sciences. 2 (3): 64-69. 